\title{
Secondary reconstruction of below knee amputation stump with free anterolateral thigh flap
}

\author{
Dinesh Kadam \\ Department of Plastic \& Reconstructive Surgery, A J Institute of Medical Sciences and A J Hospital \& Research Centre, \\ Kuntikana, Mangalore, India
}

Address for correspondence: Dr. Dinesh Kadam, Department of Plastic \& Reconstructive Surgery, A J Institute of Medical Sciences and AJ Hospital \& Research Centre, Kuntikana, Mangalore-575004, India. E-mail: drkadam@yahoo.co.in

\section{ABSTRACT}

Below knee stump preservation reduces ambulatory energy expenditure and improves the quality of life. Reconstruction of soft tissue loss around the stump is a challenging task. Below knee stump reconstruction demands stable skin with sufficient soft tissue to allow weigh bearing. Microsurgical tissue transfer is increasingly being used as a salvage option. Anterolateral thigh flap with additional vastus lateralis muscle provides extra cushioning effect. We report two cases of amputation below knee successfully salvaged. The anterolteral flap with abundant tissue and stable skin offers a reliable option for cover. Two patients with below knee amputation were reconstructed secondarily. After 6 to 20 months of follow -up, stumps showed no signs of pressure effects. Patients are able to bear 50-70 hours of weight per week.

\section{KEY WORDS}

Amputation stump salvage; knee stump reconstruction; free flaps for stump; aterolateral thigh flap

\section{INTRODUCTION}

D

raumatic leg amputation needs preservation of the stump despite variable soft tissue loss. It is essential to provide a durable, pain free stump and a stable knee joint. Inadequate soft tissue on the loading area of the stump invariably results in repeated breakdown, ulceration, chronic infection and inability to fit prosthesis. Free tissue transfer often is the only salvage solution for a long-term success. We report two cases of secondary reconstruction of a below knee stump using anterolateral thigh free flap. Additional vastus lateralis muscle was included to cover the projecting tibial stump. The reconstructed stumps are stable and pain free at 6 and 20 months of follow-up.

\section{CASE REPORTS}

\section{Case 1}

A 32-year-old man sustained injury to his right leg in a road traffic accident five years ago. He had mangled leg which resulted in a below knee amputation done at a local hospital. The stump had healed with secondary intention owing to insufficient soft tissue cover and infection [Figure 1]. He was fitted with prosthesis and was allowed ambulation. However, the loading area of the stump had repeated breakdown and the stump became extremely sensitive and painful. He was unable to wear the prosthesis and bear weight on the stump. The bone length was maintained at $12 \mathrm{~cm}$ below the tibial plateau and soft tissue cover was possible only at the expense of the shortening of the stump. Salvage of the stump was only possible with adequate soft tissue cover. Reconstruction of the stump was planned with anterolateral thigh flap from the opposite side. The scar tissue was excised completely till the bone. About $2 \mathrm{~cm}$ tibial end was projecting in the wound [Figure 2]. A $14 \times 14 \mathrm{cms}$ flap along with vastus lateralis muscle was harvested with the patient in supine position. Subsequently the patient was made to lie 


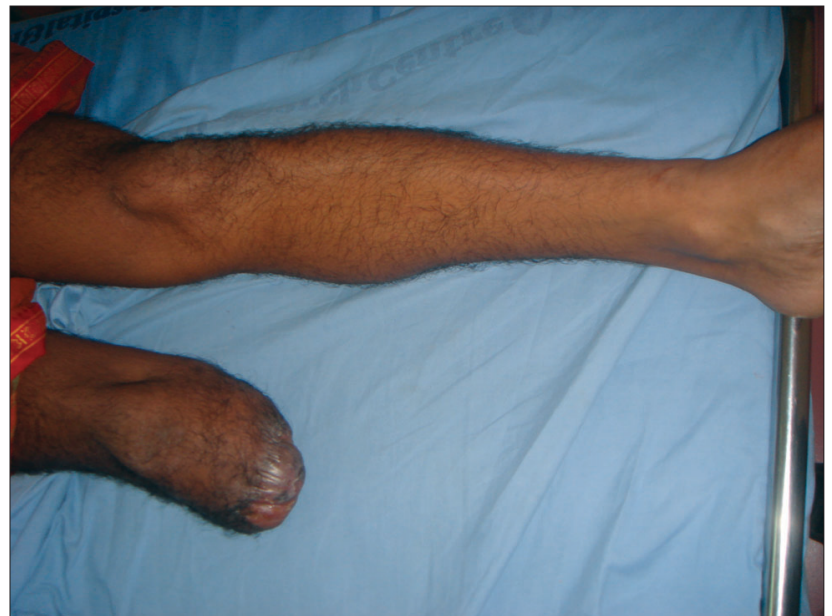

Figure 1: The right below-knee stump in a 32 year old amputee who presented with unstable scar, recurrent chronic inflammation and failure to use prosthesis

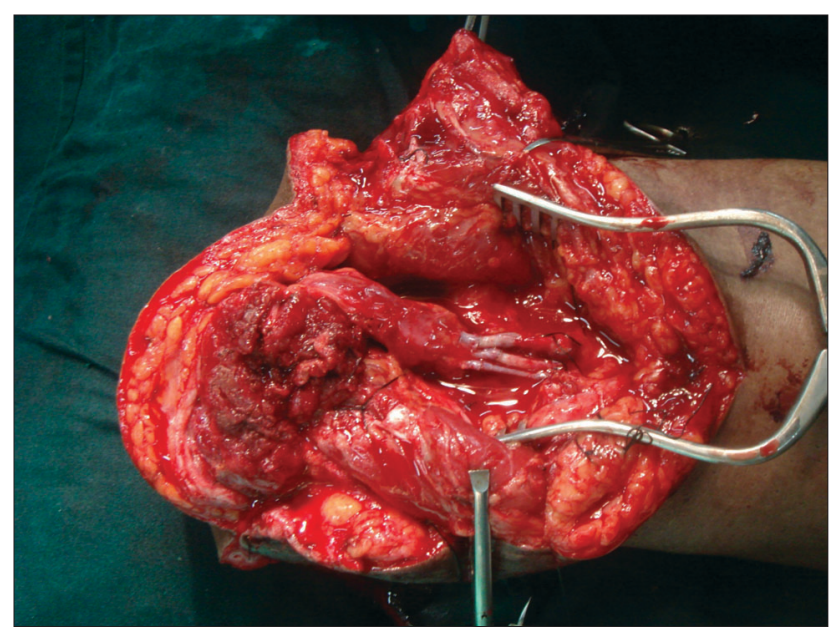

Figure 3: End to end anastomosis to popliteal vessels, and muscle covering the bony stump

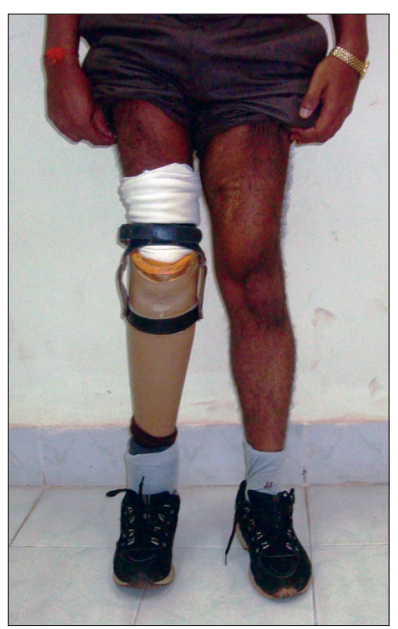

Figure 5: Patient is ambulatory and he is on the prosthesis for about 70 hours per week

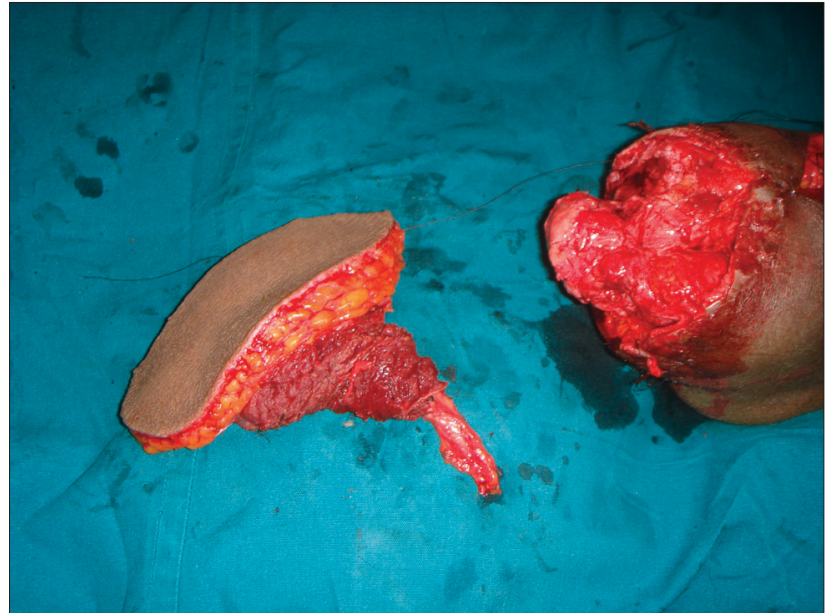

Figure 2: Excised unstable scar and exposed prominent tibial projection along with harvested anterolateral thigh flap with vastus lateralis muscle. Vastus muscle is used to cover projecting bony stump

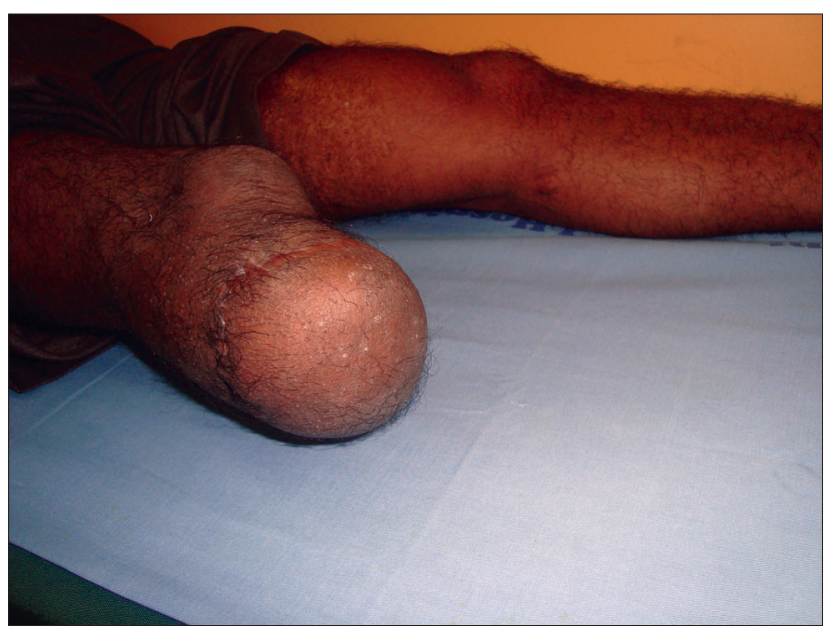

Figure 4: Well settled flap at 20 months post surgery without any pressure ulcerations or flap redundancy

prone for recipient vessel dissection in the popliteal fossa. Anastomosis was done end-to-end to popliteal vessels with minimal vessel diameter discrepancy [Figure 3]. The vastus lateralis muscle in the flap covered the bony stump and flap was insetted snugly to the defect without any redundancy. Duration of the operation was six hours. The postoperative period was uneventful, and skin grafted donor site healed satisfactorily. The patient was discharged on 16th post operative day. He was refitted with prosthesis 10 weeks after the surgery. He is a school teacher by profession and he is on the prosthesis for approximately 70 hours per week. He is symptom free at 20 months after the surgery and flap does not show any atrophy or redundancy [Figure 4]. He experienced remarkable improvement and can stand for 5 hours at a stretch without any pain. His pain free walking 
distance has increased from half a mile preoperatively to two miles post-operatively [Figure 5]. Although no nerve was anstomosed, the patient appreciates pain on deep pressure and can distinguish hot and cold sensation.

\section{Case 2}

A 26 year young adult sustained traumatic crush amputation of the left leg in a train accident. He was left with $9 \mathrm{~cm}$ tibial stump after debridement with degloved skin. Wounds were covered primarily with available soft tissue around the stump with skin graft at a referring hospital. Patient presented after 6 months of injury. He was unable to fit the prosthesis and bear weight due to pain at the bony prominences and load bearing area. Anterolteral thigh flap with vastus lateralis muscle was used to cover the stump. A $12 \times 13 \mathrm{~cm}$ flap was anastomosed to popliteal vessels. Patient had uneventful hospital stay and was discharged after 26 days. A below knee prosthesis was fitted after 11 weeks. He is on the prosthesis for 30 hours per week and he is pain free at 6 months post surgery.

\section{DISCUSSION}

Preserving below knee amputation stump has advantages of natural gait mechanics, decreased work of ambulation and better prosthetic rehabilitation. ${ }^{[1]}$ All attempts to preserve the stump should be aimed at providing optimal stump length, stable soft tissue cover and functioning knee joint. Insufficient tissue cover at the load area of stump results in repeated ulceration, chronic infection, frequent change or inability to fit the prosthesis. ${ }^{[2-4]}$ When preserved stump length is not more than optimum, revision of the stump is not possible. Salvage of such stumps may necessitate use of free vascularized flaps. Prior to use of free tissue transfer, local myofascial flap, cross leg flap, skin traction or expansion techniques were in use to provide durable stump cover ${ }^{[3,4]}$ Free flaps have been successfully utilized to salvage stumps in emergency settings, following tumour ablation and for unstable scars in loading areas. In an emergency setting when the replantation is not possible in a relatively uninjured limb, "fillet free flap" is considered as a natural first choice. ${ }^{[4]}$ Various free flaps used to reconstruct the stump are: scapular flap, Latissimus dorsi (LD) myocutaneous flap, Groin flap, Radial artery forearm flap and anterolateral thigh flap. Generally, thinner flaps are needed for the cover of upper limb stumps to facilitate fitting myo-electrical prosthesis. ${ }^{[5]}$ Whereas in lower limbs, a thicker skin and soft tissue cover is needed to withstand weight bearing as well as to resist shearing force between the prosthesis and the stump. ${ }^{[6,7]} \mathrm{LD}$ flap with skin paddle has an advantage of abundant tissue and longer vascular pedicle but remains unpredictable in terms of inevitable muscle atrophy and redundancy of tissues over the years. ${ }^{[8,9]}$ In a report of ten cases for reconstruction with LD flap, five debulking procedures in 4 patients were required between three months and three years of follow-up..$^{[8]}$ Anterolateral thigh flap (ALT) is a versatile flap with abundant thick skin and a long pedicle. Moreover, additional muscle bulk can be included either as a musculucutaneous flap or a chimeric flap with an additional perforator to the muscle to cover bony stump. The flap at 20 months of follow-up in first patient has not only provided stable and pain free stump but also improved his productivity immensely by enabling more than 70 hours of prosthetic wearing per week. Additional muscle inclusion in the flap, which was just enough to cover the stump, helps to prevent development of pressure ulceration. Although no nerve was anastomosed patient developed protective sensation which helps in better stump care, durability and patient satisfaction.

\section{REFERENCES}

1. Waters RL, Perry J, Antonelli D, Hislop H. Energy cost of walking of amputees: the influence of level of amputation. J Bone Joint Surg Am 1976;58:42.

2. Yildirim S, Calikapan GT, Akoz T. Reliable option for reconstruction of amputation stumps: the free anterolateral thigh flap. Microsurgery 2006;26:386-90.

3. Shenaq SM, Krouskop T, Stal S, Spira M. Salvage of amputation stumps by secondary reconstruction utilizing microsurgical freetissue transfer. Plast Reconstr Surg 1987;79:861-70.

4. Erdmann D, Sundin BM, Yasui K, Wong MS, Levin LS. Microsurgical free flap transfer to amputation sites: indications and results. Ann Plast Surg 2002;48:167-72.

5. Baccarani A, Follmar KE, De Santis G, Adani R, Pinelli M, Innocenti $\mathrm{M}$, et al. Free vascularized tissue transfer to preserve upper extremity amputation levels. Plast Reconstr Surg 2007;120:971-81.

6. Gallico GG 3rd, Ehrlichman RJ, Jupiter J, May JW Jr. Free flaps to preserve below-knee amputation stumps: long-term evaluation. Plast Reconstr Surg 1987;79:871-8.

7. Kasabian AK, Colen SR, Shaw WW, Pachter HL. The role of microvascular free flaps in salvaging below-knee amputation stumps: a review of 22 cases. J Trauma 1991;31:495-500.

8. Tukiainen EJ, Saray A, Kuokkanen HO, Asko-Seljavaara SL. Salvage of major amputation stumps of the lower extremity with latissimus dorsi free flaps. Scand J Plast Reconstr Surg Hand Surg 2002;36:85-90.

9. Hallock GG. Preservation of lower extremity amputation length using muscle perforator free flaps. J Plast Reconstr Aesthet Surg 2008;61:643-47.

Source of Support: Nil, Conflict of Interest: None declared. 